\title{
FACTORS ASSOCIATED WITH PHYSICAL ACTIVITY LEVELS IN LATE ADOLESCENCE: A PROSPECTIVE STUDY
}

\author{
Damir Sekulic ${ }^{1}$, Jelena Rodek ${ }^{1}$, Tine Sattler ${ }^{2}$ \\ ${ }^{1}$ University of Split, Split, Croatia \\ Faculty of Kinesiology \\ ${ }^{2}$ University of Ljubljana, Ljubljana, Slovenia \\ Faculty of Sport
}

\begin{abstract}
Background: Reaching an appropriate physical activity level (PAL) in adolescence is an important public health problem. This study aimed to evaluate factors associated with PAL and changes in PAL in late adolescence. Material and Methods: The sample involved 407 adolescents (184 girls) who were 16 years of age at study baseline; the participants completed a structured validated questionnaire at baseline (the beginning of the third grade of high school) and again at follow-up (the end of the fourth grade; when they were 18 years of age). Variables were obtained at both testing waves and included the following predictors: sociodemographic indices (sex, socioeconomic status, parental education), sports factors (participation in individual and team sports, competitive sports achievement, experience in sports), and PAL (the primary outcome), which was measured using the Physical Activity Questionnaire for Adolescents. Results: A significant decrease in PAL between baseline and follow-up testing was evidenced ( $\mathrm{t}$-test $=6.17$, $\mathrm{p}<0.001)$. A logistic regression model calculated with a dichotomized outcome (normal PAL vs. low PAL), and sex as a covariate, showed a significant influence of participation in team sports and maternal education on PAL, both at baseline $(\mathrm{OR}=1.56$, 95\% CI: 1.11-1.87; OR = 1.38, 95\% CI: $1.02-1.90)$ and at follow-up (OR = 1.45, 95\% CI: $1.01-1.90$; OR = 1.35, 95\% CI: $1.08-1.70$, for team sports and maternal education, respectively). Conclusions: The study confirmed certain associations between the studied variables and PAL, but there was no significant influence of the observed indicators on changes in PAL in late adolescence. Further studies evaluating other predictors of changes in PAL are warranted. Med Pr. 2020;71(6):637-47
\end{abstract}

Key words: predictors, sport, physical activity, puberty, sociodemographics, physical literacy

Corresponding author: Damir Sekulic, University of Split, Faculty of Kinesiology, Teslina 6, 21000 Split, Croatia, e-mail: dado@kifst.hr

Received: May 16, 2020, accepted: June 15, 2020

\section{INTRODUCTION}

Physical activity (PA) directly and indirectly influences health-related indices and is considered an important determinant of the overall health status [1]. Apart from being related to the development of obesity, a low physical activity level (PAL) is known to be connected to various non-communicable diseases, such as hypertension, cardiovascular diseases, and some types of cancer [2]. Although most of the negative health effects connected with low PAL develop later in life, lifelong patterns related to health behavior are established during childhood and adolescence [3]. Therefore, the promotion of reaching an appropriate PAL should begin at an early age [4]. For this reason, there is growing interest in research focusing on factors associated with PAL in different periods of life, and one of the promising approaches is the identification of the factors associated with "changes in PAL" over a certain period of time $[5,6]$.
Recently, a prospective study demonstrated changes and factors of influence in PAL among adolescents from Bosnia and Herzegovina that occurred over a period of 2 years [6]. Predictors were sociodemographic characteristics, and variables of substance misuse (consumption of cigarettes, alcohol and illicit drugs), and PAL (outcome) was measured using the Physical Activity Questionnaire for Adolescents (PAQ-A). Apart from several correlations between the studied predictors and changes in PAL that occurred during the study period (at 16-18 years of age), the authors concluded that certain relationships should be contextualized in light of the fact that in the studied period a large number of children quit competitive sports, which simultaneously influenced changes in the sociocultural environment, and PAL. However, it is important to note that this study did not specifically observe (measure) sports factors, and the stated interpretations were based solely on the authors' own experience. 
While PA includes any bodily movement produced by skeletal muscles, physical exercise (which is mostly nowadays evidenced by participation in sports activities) refers to planned and structured PA performed for some specific reason (i.e., energy expenditure, improvement of body function, competitive result) [7]. Logically, sports participation is considered an important factor which directly contributes to PAL, particularly among children and adolescents [8]. The participation in organized (competitive) sports is "physically demanding," and the overall PAL of children involved in sports is regularly found to be higher than that of non-athletic children [9-11]. As a result, it is not surprising that studies have reported a positive correlation between participation in sports and PAL, emphasizing the importance of participation in organized sports activities in reaching an appropriate PAL in youth [9]. This problem is additionally important because of the globally confirmed significant decrease in PAL in adolescence [12]. Therefore, studies identifying factors associated with PAL changes in adolescence are essential, because any information that will help in reducing the negative trends in PA changes will be highly beneficial, both from a scientific perspective and from a public health perspective.

With regard to the association between sports participation and PAL in adolescence, another issue deserves attention because the association between (previous) sports participation and PA changes that occur later in life (i.e., when the participants are no longer actively involved in sports) are not known. In other words, the following question arises: "Is sports participation earlier in adolescence related to a higher or lower PAL later in life?". However, studies have rarely examined this problem. The most likely reason for the lack of such information is the fact that answering this question actually requires prospective analyses. In other words, the participants should be observed over repeated measurements (e.g., testing waves), including the period when they were actively involved in organized sports, and later in life, when they were no longer involved in organized sports.

The aim of this study was to prospectively evaluate the influence of sports participation, and sociodemographic factors on PAL and changes in PAL in adolescents. The leading hypotheses of the research were that sports participation was positively related to PAL, and negatively related to changes in PAL over the observed 2-year period (at 16-18 years of age).

\section{MATERIAL AND METHODS}

\section{Participants and design of the study}

The sample of participants was selected in the territory of southern Croatia (specifically Split-Dalmatia County). The total sample included 407 adolescents (184 girls) who were 16.2 \pm 1.3 years old and attending their third year of high school at study baseline (the first wave of testing). The second wave of testing (follow-up measurement) commenced at the end of their fourth year of high school, when the participants were approximately 18 years of age. The sampling procedure included several phases. First, the authors stratified all high schools in the territory of Split-Dalmatia County into 2 clusters according to the size of the schools. Then, one-third of the high schools clustered in each group were randomly selected. In the next phase, onehalf of the third grade classes in each school were randomly selected. For those schools where there was only one third grade class, the random selection was not done and the existing class was included in the study. After contacting the school authorities and obtaining permission for the study, parental informed consent was obtained. At the first wave of testing, 441 participants were tested, but only those who participated in both testing waves were included in this investigation.

The baseline testing was performed over the first 2 weeks of the 2017/18 school year, and involved adolescents who personally agreed to participate and whose parent(s) signed the consent form. Although the testing was anonymous, the participants were instructed to use self-selected anonymous codes for identification purposes in both testing waves (i.e., the last 3 digits of their e-mail password). The examiners informed the participants of the study purpose and aims, that the testing was absolutely voluntary and anonymous, and that they could leave the questionnaire form or some questions unanswered. The testing lasted approx. $15 \mathrm{~min}$. The follow-up testing was performed at the end of the fourth year of high school (during the last 3 weeks of the school year). The procedure and the study were in accordance with the Declaration of Helsinki, and were originally approved by the Ethics Board of the University of Split, Faculty of Kinesiology, Split, Croatia. After obtaining the positive opinion of the Ethics Board, the study was approved by school authorities as well.

After the follow-up testing, the analysis of attrition bias was performed. The results showed that the re- 
sponders (those who were tested in both testing waves) and the non-responders (those who were tested at baseline only) did not differ in PAL at baseline ( $\mathrm{t}$-test $=0.14$, $\mathrm{p}>0.05)$ or in factors related to sports participation $\left(\chi^{2}=0.14-1.55, \mathrm{p}>0.05\right)$. However, significantly more boys than girls dropped out between baseline and follow-up $\left(\chi^{2}=16.11, \mathrm{p}<0.01\right)$, which was probably related to the fact that boys are known to be more absent from school than girls [13]. Additionally, the intracluster correlation (IC) for the baseline PAL (with the schools as the clusters) showed good within-school variance (IC $=0.05$ and 0.06 for baseline and follow-up, respectively) [14].

\section{Variables}

The variables included the participants' sociodemographic characteristics, sports factors, and PAL. All variables were collected by previously validated questionnaires $[6,13,15]$.

Sociodemographic factors were self-reported sex, age (in years), self-reported socioeconomic status (responses included: below average, average, above average), maternal education and paternal education (both reported on a scale with the following responses: elementary school, high school, college, university degree). Sports factors were tested at baseline and included questions about students' sports participation [13]:

involvement in competitive team sports (i.e., basketball, football/soccer, handball);

involvement in competitive individual sports (i.e., track and field, swimming, artistic gymnastics) (both reported as "no," "quit," “yes;" later, for the purpose of logistic regression calculation, grouped into "non-involved" [the first 2 responses], and "involved");

the highest competitive sports achievement/result (from never involved/competed, locally, to international level);

the duration of sports involvement (never participated, $\leq 1$ year, $2-5$ years, $>5$ years).

The actual PAL was determined by PAQ-A. Previously, PAQ-A was repeatedly found to be a valid and reliable questionnaire in samples of participants similar to the one observed herein $[15,16]$. Generally, PAQ-A consists of 9 items asking the participants to provide a 7-day self-reported recall. The final theoretical numerical score on PAQ-A ranges from 0 (the minimum PAL) to 5 (the maximum PAL). The first 8 items ask the participants about different types of PA, such as PA during physical education classes, sports, and active transportation. The ninth item does not contribute to the overall score but is used solely to target those participants who were not able to participate in regular PA due to illness or injury. In this study, the authors focused on 3 variables derived by PAQ-A:

PAL at baseline (PAL-BL),

PAL at follow-up (PAL-FU),

changes in PAL between baseline and follow-up (calculated as differences between PAL-BL and PAL-FU).

For the purpose of logistic regression calculation (please see later for Statistics), the PAL-BL and PAL-FU results were dichotomized. Specifically, scores $<2.73$ were observed as low PAL, while scores $>2.73$ were observed as normal PAL, as suggested previously [17].

\section{Statistics}

Descriptive statistics included means and standard deviations (for numerical variables), and percentages and frequencies (for ordinal and nominal variables). To identify the changes in PAL between baseline and follow-up, a t-test for dependent samples was calculated. Differences between boys and girls in the studied variables were evidenced either by the t-test for an independent sample (for PAL), or by Mann-Whitney $U$ test, and the $\chi^{2}$ test (for non-parametric variables).

To calculate the associations between the studied variables, Spearman's rank order correlation was applied. To identify the associations between predictors, and PAL-BL and PAL-FU, logistic regression was calculated. Previous studies identified a strong effect of sex on PAL in adolescence [6]; therefore, 2 logistic regression models were calculated: crude (model 0 - uncontrolled for covariates, and model 1 - controlled for sex as a covariate). Finally, those predictors that were found as being significantly correlated with criteria were simultaneously included in (multivariate) logistic regression calculations.

A p-value of $95 \%$ was applied, and the Statistica ver. 13.0 statistical package (Statsoft, USA) was used for all calculations.

\section{RESULTS}

Generally, PAL significantly decreased over the study period in the total sample $(2.48 \pm 0.70-2.27 \pm 0.73$, t-test: $6.11, \mathrm{p}<0.001)$, among boys $(2.74 \pm 0.70-2.52 \pm 0.77$, 


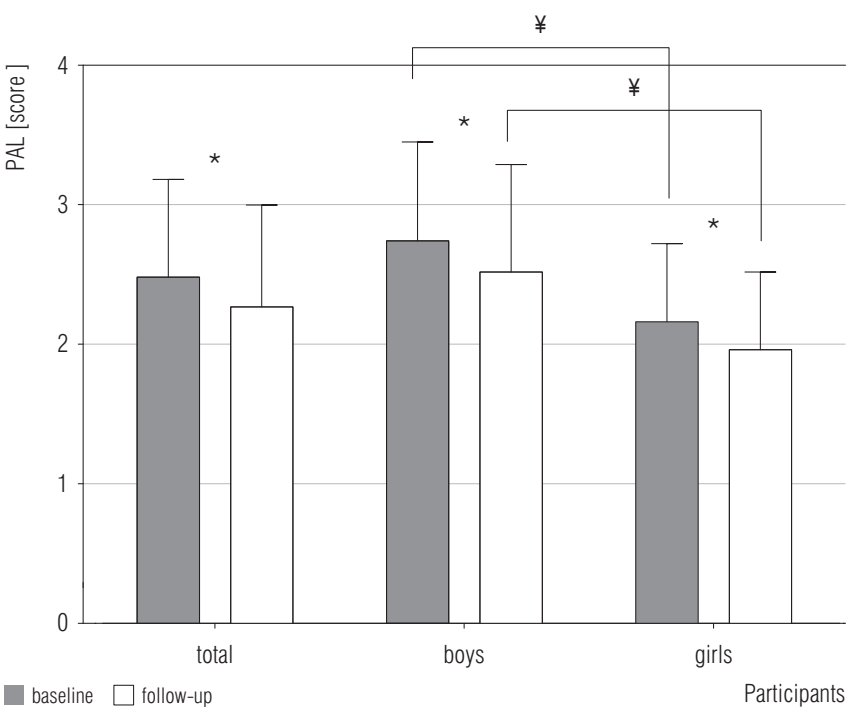

Presented as $\mathrm{M} \pm \mathrm{SD}$

Significant $(\mathrm{p}<0.001)$ differences between $(¥)$ and within groups $\left(^{*}\right)$.

Figure 1. Descriptive statistics for physical activity levels (PAL) as obtained by the Physical Activity Questionnaire for Adolescents (PAQ-A) for adolescents from southern Croatia (late 2016)

t-test: $4.44, \mathrm{p}<0.001)$, and girls $(2.16 \pm 0.56-1.96 \pm 0.56$, t-test: $4.72, \mathrm{p}<0.001)$. Higher PAL was evidenced in boys than in girls, at both testing waves (t-test: 9.14 and 8.26 for PAL-BL and PAL-FU, respectively) (Figure 1).

Boys and girls differed significantly in all sports factors, with boys being more involved both in individual and team sports (Mann-Whitney U test: 5.83 and 7.26, $\mathrm{p}<0.01$, respectively). Also, boys recorded better competitive sports achievement, and were involved in sports for a longer time than girls (Mann-Whitney U test: 8.31 and $4.29, \mathrm{p}<0.01$, respectively) (Table 1 ).

Spearman's correlation evidenced significant positive associations between baseline sports participation, and PA-BL and PAL-FU. In general, all sports factors were correlated with PAL, with stronger correlations observed for PAL-BL (Spearman's $\rho: 0.22-0.44$ ), than for PAL-FU (Spearman's $\rho: 0.20-0.40$ ). The socioeconomic status was not correlated with PAL, but specific associations were found between paternal education and PAL. In brief, both paternal and maternal education levels were positively correlated with PAL-BL, but only maternal education was significantly correlated with PAL-FU. No significant correlations between the studied variables and changes in PAL which occurred between baseline and follow-up were evidenced (Table 2).

Results of the logistic regression for the dichotomized PAL-BL and PAL-FU criteria are presented in Figure 2. The male sex was a significant predictor of PAL-BL and PAL-FU (model 0: OR $=1.51$, 95\% CI: $1.23-1.87$, and OR $=1.31,95 \%$ CI: $1.01-1.61$ for PAL-BL and PAL-FU, respectively). Therefore, the authors focused on the results of model 1 (calculated with "sex" as a covariate). Maternal education $(\mathrm{OR}=1.38,95 \% \mathrm{CI}: 1.02-1.90)$, and team sports participation $(\mathrm{OR}=1.56,95 \% \mathrm{CI}$ : 1.11-1.87) were significant predictors of PAL-BL (Figure 2). Similarly, higher maternal-education $(\mathrm{OR}=1.35,95 \% \mathrm{CI}: 1.08-1.70)$, and involvement in team sports $(\mathrm{OR}=1.45,95 \% \mathrm{CI}$ : $1.01-$ 1.90 ) were significant predictors of PAL-FU.

The multivariate logistic regression, with maternal education and team sports participation as predictors, showed a significant association between team sports and PAL-BL (OR = 1.50, 95\% CI: 1.09-1.99). Meanwhile, team sports $(\mathrm{OR}=1.44,95 \% \mathrm{CI}: 1.01-1.98)$, and maternal education ( $\mathrm{OR}=1.40,95 \% \mathrm{CI}$ : $1.02-1.88)$ were significant multivariate predictors of PAL-FU.

Table 1. Descriptive statistics for the studied sociodemographic and sports factors for adolescents from southern Croatia (late 2016) with differences between boys and girls

\begin{tabular}{|c|c|c|c|c|c|c|c|}
\hline & \multicolumn{6}{|c|}{$\begin{array}{c}\text { Participants } \\
\quad[\mathrm{n}] \\
(\mathrm{N}=407)\end{array}$} & \multirow{3}{*}{$\mathrm{Z}$} \\
\hline Variable & \multicolumn{2}{|c|}{ total } & \multicolumn{2}{|c|}{$\begin{array}{c}\text { boys } \\
(\mathrm{N}=223)\end{array}$} & \multicolumn{2}{|c|}{$\begin{array}{c}\text { girls } \\
(\mathrm{N}=184)\end{array}$} & \\
\hline & $\mathrm{F}$ & $\%$ & $\mathrm{~F}$ & $\%$ & $\mathrm{~F}$ & $\%$ & \\
\hline Socioeconomic status & & & & & & & 0.47 \\
\hline below average & 6 & 1.5 & 5 & 2.2 & 1 & 0.5 & \\
\hline average & 382 & 92.9 & 201 & 90.1 & 177 & 96.2 & \\
\hline above average & 23 & 5.6 & 17 & 7.6 & 6 & 3.3 & \\
\hline missing & 0 & 0.0 & 0 & 0.0 & 0 & 0.0 & \\
\hline
\end{tabular}


Table 1. Descriptive statistics for the studied sociodemographic and sports factors for adolescents from southern Croatia (late 2016) with differences between boys and girls - cont.

\begin{tabular}{|c|c|c|c|c|c|c|c|}
\hline \multirow{3}{*}{ Variable } & \multicolumn{6}{|c|}{$\begin{array}{c}\text { Participants } \\
\text { [n] } \\
(\mathrm{N}=407)\end{array}$} & \multirow{3}{*}{$\mathrm{Z}$} \\
\hline & \multicolumn{2}{|c|}{ total } & \multicolumn{2}{|c|}{$\begin{array}{c}\text { boys } \\
(\mathrm{N}=223)\end{array}$} & \multicolumn{2}{|c|}{$\begin{array}{c}\text { girls } \\
(\mathrm{N}=184)\end{array}$} & \\
\hline & $\mathrm{F}$ & $\%$ & $\mathrm{~F}$ & $\%$ & $\mathrm{~F}$ & $\%$ & \\
\hline Paternal education & & & & & & & 1.49 \\
\hline high school & 299 & 72.7 & 164 & 73.5 & 131 & 71.2 & \\
\hline college degree & 48 & 11.7 & 28 & 12.6 & 20 & 10.9 & \\
\hline university degree & 38 & 9.2 & 23 & 10.3 & 15 & 8.2 & \\
\hline missing & 0 & 0.0 & 0 & 0.0 & 0 & 0.0 & \\
\hline high school & 246 & 59.9 & 142 & 63.7 & 101 & 54.9 & \\
\hline college degree & 25 & 6.1 & 14 & 6.3 & 11 & 6.0 & \\
\hline university degree & 25 & 6.1 & 14 & 6.3 & 11 & 6.0 & \\
\hline missing & 0 & 0.0 & 0 & 0.0 & 0 & 0.0 & \\
\hline \multicolumn{8}{|l|}{ Participation in sports } \\
\hline individual & & & & & & & $-5.83^{* * *}$ \\
\hline yes, currently & 88 & 21.4 & 71 & 31.8 & 16 & 8.7 & \\
\hline quit & 137 & 33.3 & 77 & 34.5 & 57 & 31.0 & \\
\hline missing & 0 & 0.0 & 0 & 0.0 & 0 & 0.0 & \\
\hline Experience in sports & & & & & & & $8.31^{* * *}$ \\
\hline never participated & 107 & 26.0 & 27 & 12.1 & 80 & 43.5 & \\
\hline$\leq 1$ year & 91 & 22.1 & 42 & 18.8 & 48 & 26.1 & \\
\hline $2-5$ years & 113 & 27.5 & 74 & 33.2 & 38 & 20.7 & \\
\hline$>5$ years & 100 & 24.3 & 80 & 35.9 & 18 & 9.8 & \\
\hline missing & 0 & 0.0 & 0 & 0.0 & 0 & 0.0 & \\
\hline Competitive sports achievement & & & & & & & $4.19^{\star * *}$ \\
\hline never involved/competed & 212 & 51.6 & 90 & 40.4 & 122 & 66.3 & \\
\hline local & 168 & 40.9 & 115 & 51.6 & 49 & 26.6 & \\
\hline national level & 31 & 6.6 & 15 & 6.7 & 12 & 6.5 & \\
\hline international level & 4 & 1.0 & 3 & 1.3 & 1 & 0.5 & \\
\hline missing & 0 & 0.0 & 0 & 0.0 & 0 & 0.0 & \\
\hline
\end{tabular}

$* * * \mathrm{p}<0.001$.

Z - Mann-Whitney U test. 
Table 2. Spearman's rank correlation coefficients between the studied sociodemographic and sports factors, and physical activity (PA) indices in the total sample, and separately for boys and girls (adolescents from southern Croatia, late 2016)

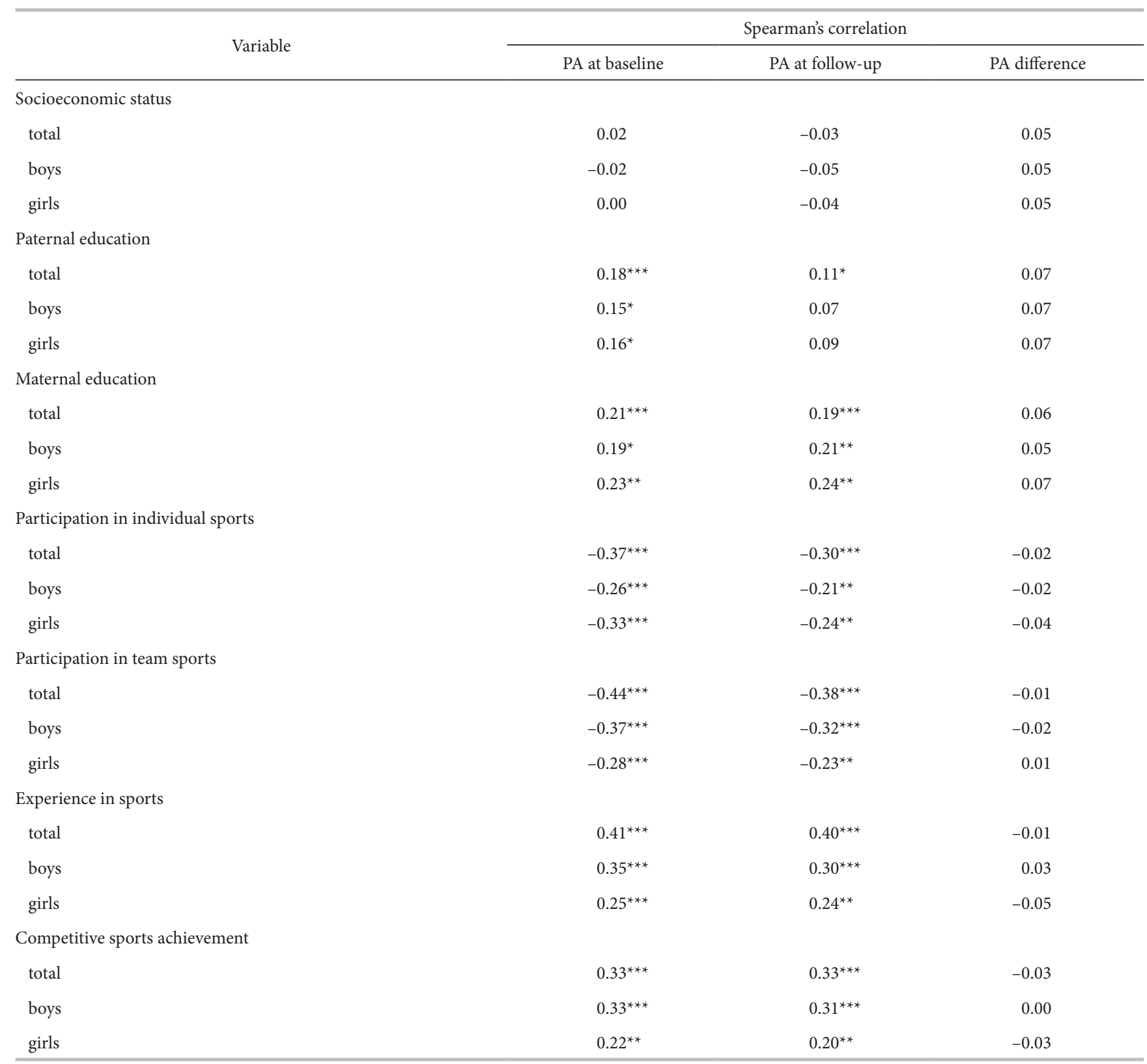

${ }^{*} \mathrm{p}<0.05,{ }^{* *} \mathrm{p}<0.01,{ }^{* * *} \mathrm{p}<0.001$.

\section{DISCUSSION}

The results of this study revealed several important findings with regard to the study aims. First, the studied sports participation and sociodemographic factors were significantly correlated with PAL at baseline and follow-up, with some differences between the sexes and the type of sport. Next, changes in PAL that occurred in the course of the study were not significantly correlated with the observed predictors. Before discussing the re- sults directly related to the study aims, the differences between sexes, and the changes in PAL that occurred in the studied period of 2 years, are overviewed.

Although the differences between sexes were not the direct study aim, the fact that boys had higher PAL than girls deserves attention. Generally, studies consistently reported higher PAL among adolescent boys $[3,6]$. Such differences are particularly evident in late adolescence and this is mostly explained by the fact that boys are more involved in organized sports than 
girls. Knowing the significant differences in sports factors between sexes in this study (i.e., boys were systematically more engaged in sports than girls), the significant differences in PAL between sexes were expected.

The results of this study showed a significant decrease in PAL at the age of 16-18 years, and this is in accordance with recent studies where such trends were evidenced on the national level. In brief, Stefan et al. [18] evidenced a PAL decrease in adolescents from the Croatian capital city, Zagreb, between the first and second grade of high school, and this is in accordance with recent investigation done with somewhat older adolescents from southern regions of the country [3]. Although in this study there were some numerical differences between the sexes (a somewhat larger decrease in PAL among boys), the negative trends in PAL observed in the study are supportive of previous reports where authors observed similar negative trends in PAL globally.

For example, U.S. authors observed a substantial decrease in moderate to vigorous PA in adolescence, particularly for girls (decreasing 5.9-4.9 h/week from early to mid-adolescence, and 5.1-3.5 h/week from mid- to late adolescence). This was accompanied by an increase in free-time computer use, particularly among boys (increasing 11.4-15.2 h/week from early to mid-adolescence, and 10.4-14.2 h/week from mid- to late adolescence) [19]. Additionally, Norwegian authors showed an evident decrease in PAL from early adolescence (approx. 13 years of age) to early adulthood (23 years of age) [20]. Finally, the results of a recent study performed in adolescents from Bosnia and Herzegovina showed similar negative trends among boys and girls that were prospectively observed in late adolescence [6].

Sports participation plays an important role in PAL in childhood and adolescence [21]. Indeed, a large proportion of the PAL variance in youth is explained by participation in organized sports and the influence of sports involvement on the total PAL increases [10]. The main explanation for the increasing influence of sports participation on PAL in adolescence is related to a corresponding decrease in everyday PA due to reduced active transportation (i.e., walking, cycling), and the lack of physical work (as a result of mechanization) [22]. Taking into account the prevailing trends in the modern society, the involvement in sports has become an even more important factor influencing PAL.

Knowing the results of previous studies where authors regularly observed higher PAL among athletic youth than among non-athletic youth, the results of a consistent positive correlation between sports factors
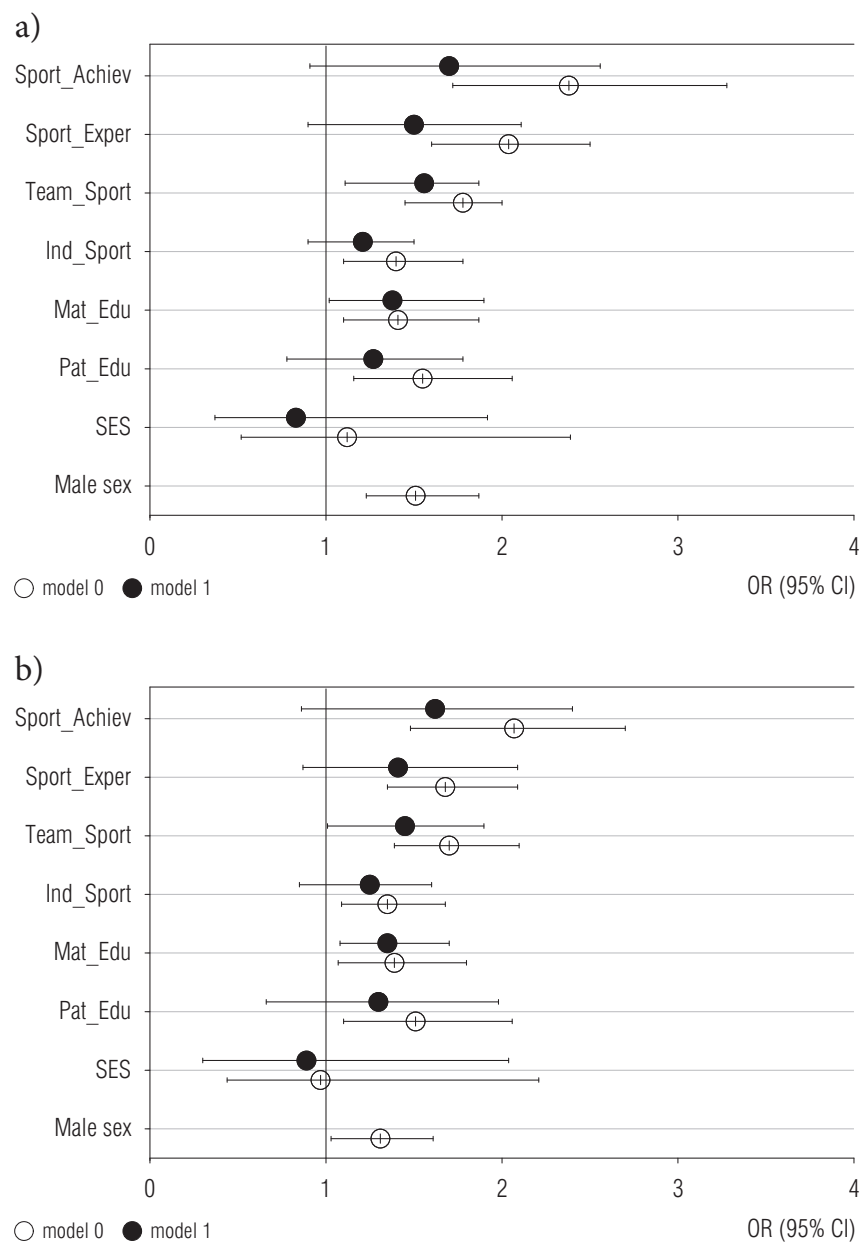

Ind_Sport - current participation in individual sports, Mat_Edu - maternal education level, Pat_Edu - paternal education level, SES - socioeconomic status, Sport_Achiev competitive sports achievement, Sport_Exper - experience (engagement) in sports, Team_Sport - current participation in team sports.

Model 0 - non-controlled for covariates, model 1 - controlled for sex as a covariate.

Figure 2. Results of the logistic regression calculation - correlates of physical activity levels at a) baseline and b) follow-up among adolescents from southern Croatia

and PAL (both measured at baseline and follow-up) were expected [9-11]. Meanwhile, it is important to highlight that this study demonstrated a stronger influence of team sports participation on PAL, which is a novel finding, to some extent. The explanation for such a result may be found in the specific sociocultural context of team sports participation in the studied region (southern Croatia). Namely, the most popular team sports in the studied region (i.e., football/soccer, basketball, handball) are frequently played even out of the context of organized sports, and it is not rare for children and adolescents to engage in such activities out of a "competitive environment," just for fun.

Recent studies have confirmed that while sports participation increases PAL directly, children who are 
actively involved in sports are also more likely to have higher levels of everyday PA than their non-athletic peers [23]. The mechanism of such influence was explained through differences in the fitness status between sports participants and non-exercising children. In brief, those children who were engaged in sports were more likely to have better fitness, allowing them to be more physically active overall [23]. Putting these findings in the context of this study and the previously stated results of a stronger association between team sports participation and PAL, the results can be discussed in further detail. It seems reasonable that not only the fitness status (which is logically more developed in children who practice organized sports) but also "physical literacy" and "familiarity" with most popular sports activities plays an important role in overall PAL. Namely, it is more likely that those children and adolescents who feel competent to participate in sports will be engaged in them, even in their free time (out of organized sports trainings). In this study, participation in team sports may have been observed as being more favorable to physical literacy simply because team sports are played more often than individual sports, even in free time.

The correlations between sports factors and PAL were, to some extent, influenced by sex (note that some ORs for some sports factors did not reach statistical significance when sex was included as a covariate in model 1). Taking into account the significant influence of the male sex on PAL-BL (for the crude logistic regression model, exclusively), it is logical to conclude that the identified associations between sports factors and PAL were more evident in boys. This is understandable knowing the differences in sports participation between boys and girls. Specifically, studies have regularly confirmed that boys are more engaged in organized sports than girls, and this was directly observed in the wider territory of former Yugoslavia (note that Croatia is one of the countries which was part of former Yugoslavia) $[13,24,25]$. Finally, this is also evidenced herein. Therefore, it is logical that sex is a strong factor of influence on PAL.

These results did not confirm that sports participation at the age of 16 years was a factor that influences changes in PAL at 16-18 years of age. This is a important finding since this period of life is known to be characterized by a significant decrease in PAL, while sports participation is frequently observed as "preventive" against such a decrease [26]. Therefore, these results actually do not confirm the hypothesis about the "protective effect" of sports participation in adolescence against a decrease in PAL. From the authors' perspective, as former athletes and active sport pedagogues, the most likely explanation of such findings could be found in the "orientation to success" philosophy, which is the dominant approach to youth sports in the country. In other words, sports programs in adolescence are mostly oriented towards competitive sports achievement; therefore, children are not properly educated about the additional positive outcomes of sports participation that will be important later in life (i.e., health-related fitness, positive social consequences).

While self-perceived socioeconomic status was not found to be related to PAL, it is important to note the specific influence of parental education on PAL and changes in PAL. Since this study lacked some important information that will hopefully help in a more elaborated discussion of these findings (i.e., the authors have no information about the real socioeconomic status of the families), the focus is solely on those interpretations that could be supported by other study findings. Paternal influence on sports participation is known to be strong, especially for boys [24]. Therefore, the results of a positive association between paternal education and PAL should also be observed as expected. However, although the associations between maternal education and PAL were not so frequently confirmed in literature, recent studies have reported a specific association between these indices. Specifically, in a previously cited study performed among adolescents from Bosnia and Herzegovina, the authors reported a positive influence of maternal education on changes in PAL among girls [6]. Therefore, the fact that mothers have a strong influence on their children's behavior in late adolescence can still be supported.

In Croatia, mothers are generally known to be "more responsible" for children's educational achievement than fathers. Actually, these "educational specifics" are not characteristic only for the studied country but rather reflect global paradigms [27,28]. Therefore, the background of the influence of maternal education on changes in PAL should be observed as a result of the strong influence of mothers on children's educational achievement [29]. Participation in organized competitive sports decreases in late adolescence. Thus, the PAL in later adolescence is more likely to be a consequence of "personal awareness of the health-related benefits of PAL than was the case in earlier adolescence (when children participated in sports because of the fun and/or as a result of parental control). Therefore, the positive influence of 
maternal education on PA changes in this period of life should be observed as a consequence of the positive influence of maternal education on the overall health-related behavior of children [29].

\section{Limitations and strengths}

The fact that the variables evaluated were self-reported is the most significant limitation of the study, especially for some variables were self-report bias is particularly possible (i.e., socioeconomic status of the family). Additionally, the fact that the study did not observe all theoretically important determinants of PAL, such as educational variables (i.e., educational achievement), and other types of activity that could be theoretically important covariates of the established relationships (i.e., the availability of a playground, parental PAL), cannot be ignored. Finally, this study observed only several determinants of changes in PAL; therefore, further studies are needed in order to explore the problem more specifically.

This is one of few studies in which predictors of changes in PAL in late adolescence were determined and, to the best of the authors' knowledge, this is the first investigation of its kind in Croatia. Additionally, the study indicated various sports factors as potential correlates of PAL, which is another important strength of the investigation. Therefore, the authors hope that their results will contribute to the knowledge in the field and initiate further research.

\section{CONCLUSIONS}

Generally, PAL significantly decreased between the age of 16-18 years, and such negative trends were evident in both sexes. Therefore, it is of utmost importance to develop methods and policies that could reverse such negative trends in Croatian adolescents.

Sports participation was indicated as an important determinant of PAL in late adolescence, with higher PAL among athletic adolescents. Additionally, participation in team sports was found to be more influential than participation in individual sports, which is explained by sociocultural background (practicing team sports is possible even in free time), and the importance of overall physical literacy in achieving higher PAL. However, the results of the study did not confirm the influence of sports participation on changes in PAL at $16-18$ years of age.

Parental education positively influenced PAL, with higher influence of maternal education. This obser- vation points to the specific maternal influence on health-related knowledge among adolescents, which should be explored more specifically in the future. In doing so, special attention should be paid to the evaluation of other important health-related issues in adolescents (i.e., quality of nutrition, sexual health).

\section{ACKNOWLEDGMENTS}

The authors are particularly grateful to all children who voluntary participated in the study. Special thanks go to the school authorities who approved the investigation and assisted with the research.

\section{REFERENCES}

1. Pavičić Žeželj S, Kenđel Jovanović G, Krešić G. The association between the Mediterranean diet and high physical activity among the working population in Croatia. Med Pr. 2019;70(2):169-76, https://doi.org/10.13075/mp. 5893.00773.

2. Śmigielski J, Ruszkowska J, Piotrowski W, Polakowska M, Bielecki W, Hanke W, et al. The relationship between physical activity level and selected cardiovascular risk factors and mortality of males $\geq 50$ years in Poland - the results of follow-up of participants of National Multicenter Health Survey WOBASZ. Int J Occup Med Environ Health. 2016;29(4):633-48, https://doi.org/10.13075/ijomeh. 1896.00660 .

3. Sekulic D, Blazevic M, Gilic B, Kvesic I, Zenic N. Prospective Analysis of Levels and Correlates of Physical Activity During COVID-19 Pandemic and Imposed Rules of Social Distancing; Gender Specific Study Among Adolescents from Southern Croatia. Sustainability. 2020;12(10):4072, https://doi.org/10.3390/su12104072.

4. Best K, Ball K, Zarnowiecki D, Stanley R, Dollman J. By Search of Consistent Predictors of Children's Physical Activity. Int J Environ Res Public Health. 2017;14(10):1258, https://doi.org/10.3390/ijerph14101258.

5. Kleszczewska D, Mazur J, Siedlecka J. Family, school and neighborhood factors moderating the relationship between physical activity and some aspects of mental health in adolescents. Int J Occup Med Environ Health. 2019;32(4):42339, https://doi.org/10.13075/ijomeh.1896.01389.

6. Miljanovic Damjanovic V, Obradovic Salcin L, Zenic N, Foretic N, Liposek S. Identifying Predictors of Changes in Physical Activity Level in Adolescence: A Prospective Analysis in Bosnia and Herzegovina. Int J Environ Res Public Health. 2019;16(14):2573, https://doi.org/10.3390/ ijerph16142573. 
7. Mann S, Beedie C, Jimenez A. Differential effects of aerobic exercise, resistance training and combined exercise modalities on cholesterol and the lipid profile: review, synthesis and recommendations. Sports Med. 2014;44:21121, https://doi.org/10.1007/s40279-013-0110-5.

8. Van Der Horst K, Paw MJ, Twisk JW, Van Mechelen W. A brief review on correlates of physical activity and sedentariness in youth. Med Sci Sports Exerc. 2007;39(8):124150, https://doi.org/10.1249/mss.0b013e318059bf35.

9. Sprengeler O, Buck C, Hebestreit A, Wirsik N, Ahrens W. Sports Contribute to Total Moderate to Vigorous Physical Activity in School Children. Med Sci Sports Exerc. 2019;51(8): 1653-61, https://doi.org/10.1249/MSS.0000000000001948.

10. Vella SA, Schranz NK, Davern M, Hardy LL, Hills AP, Morgan PJ, et al. The contribution of organised sports to physical activity in Australia: Results and directions from the Active Healthy Kids Australia 2014 Report Card on physical activity for children and young people. J Sci Med Sport. 2016;19(5):407-12, https://doi.org/10.1016/ j.jsams.2015.04.011.

11. Kobel S, Kettner S, Kesztyüs D, Erkelenz N, Drenowatz C, Steinacker JM. Correlates of habitual physical activity and organized sports in German primary school children. Public Health. 2015;129(3):237-43, https:/doi.org/ 10.1016/j.puhe.2014.12.002.

12. Miller J, Pereira M, Wolfson J, Laska M, Nelson T, Neumark-Sztainer D. Developmental Trends and Determinants of Physical Activity From Adolescence to Adulthood Differ by Ethnicity/Race and Sex. J Phys Act Health. 2018;15(5):345-54, https://doi.org/10.1123/jpah. 2017-0287.

13. Zenic N, Terzic A, Ostojic L, Sisic, N, Saavedra JM, Kristjansdottir $\mathrm{H}$, et al. Educational and sport factors as predictors of harmful alcohol drinking in adolescence: a prospective study in Bosnia and Herzegovina. Int J Public Health. 2019;64(2):185-94, https://doi.org/10.1007/s00038018-1168-5.

14. Killip S, Mahfoud Z, Pearce K. What is an intracluster correlation coefficient? Crucial concepts for primary care researchers. Ann Fam Med. 2004;2(3):204-8, https://doi. org/10.1370/afm.141.

15. Samaržija DV, Mišigoj-Duraković M. [Reliability of Croatian Version of the Questionnaire for Assessment of Overall Level of Physical Activity]. Hrvatski Športskomedicinski Vjesnik. 2013;28(1):24-32. Croatian.

16. PojskicH,Eslami B. Relationship Between Obesity, Physical Activity, and Cardiorespiratory Fitness Levels in Children and Adolescents in Bosnia and Herzegovina: An Analysis of Gender Differences. Front Physiol. 2018;9:1734, https:// doi.org/10.3389/fphys.2018.01734.
17. Benítez-Porres J, Alvero-Cruz JR, Sardinha LB, LópezFernández I, Carnero EA. Cut-off values for classifying active children and adolescentes using the Physical Activity Questionnaire: PAQ-C and PAQ-ACut-off values for classifying active children and adolescents using the Physical Activity Questionnaire: PAQ-C and PAQ-A. Nutr Hosp. 2016;33(5):564, https://doi.org/10.20960/ nh. 564

18. Stefan L, Soric M, Devrnja A, Petric V, MisigojDurakovic M. One-year changes in physical activity and sedentary behavior among adolescents: the Croatian Physical Activity in Adolescence Longitudinal Study (CRO-PALS). Int J Adolesc Med Health. 2018, https://doi. org/10.1515/ijamh-2017-0223.

19. Nelson MC, Neumark-Stzainer D, Hannan PJ, Sirard JR, Story M. Longitudinal and secular trends in physical activity and sedentary behavior during adolescence. Pediatrics. 2006;118(6):e1627-34, https://doi.org/ 10.1542/peds.2006-0926.

20. Kjønniksen L, Torsheim T, Wold B. Tracking of leisure-time physical activity during adolescence and young adulthood: a 10-year longitudinal study. Int J Behav Nutr Phys Act. 2008;5:69, https://doi.org/10.1186/1479-58685-69.

21. Sallis JF, Prochaska JJ, Taylor WC. A review of correlates of physical activity of children and adolescents. Med Sci Sports Exerc. 2000;32(5):963-75, https://doi.org/10. 1097/00005768-200005000-00014.

22. Booth VM, Rowlands AV, Dollman J. Physical activity temporal trends among children and adolescents. J Sci Med Sport. 2015;18(4):418-25, https://doi.org/10.1016/ j.jsams.2014.06.002.

23. Telford RM, Telford RD, Cochrane T, Cunningham RB, Olive LS, Davey R. The influence of sport club participation on physical activity, fitness and body fat during childhood and adolescence: The LOOK Longitudinal Study. J Sci Med Sport. 2016;19(5):400-6, https://doi.org/ 10.1016/j.jsams.2015.04.008.

24. Tahiraj E, Cubela M, Ostojic L, Rodek J, Zenic N, Sekulic D, et al. Prevalence and Factors Associated with Substance Use and Misuse among Kosovar Adolescents; Cross Sectional Study of Scholastic, Familial-, and Sports-Related Factors of Influence. Int J Environ Res Public Health. 2016;13(5):502, https:/doi.org/10.3390/ ijerph13050502.

25. Idrizovic K, Zenic N, Tahirajl E, Rausavljevic N, Sekulic D. Cigarette Smoking Among 17-18 Year Old Adolescents Prevalenceand Association With Sociodemographic, Familial, Sport, and Scholastic. Factors. Med Pr. 2015;66(2):153-63, https://doi.org/10.13075/mp.5893.00104. 
26. Dumith SC, Gigante DP, Domingues MR, Kohl HW 3rd. Physical activity change during adolescence: a systematic review and a pooled analysis. Int J Epidemiol. 2011;40(3): 685-98, https://doi.org/10.1093/ije/dyq272.

27. Lewko JH, Ewing ME. Sex differences and parental influence in sport involvement of children. J Sport Psychol. 1980;2(1):62-8.
28. Grolnick WS, Ryan RM. Parent styles associated with children's self-regulation and competence in school. J Educ Psychol. 1989;81(2):143.

29. Fan X, Chen M. Parental involvement and students' academic achievement: A meta-analysis. Educ Psychol Rev. 2001;13(1):1-22.

This work is available in Open Access model and licensed under a Creative Commons Attribution-NonCommercial 3.0 Poland License - http://creativecommons.org/licenses/by-nc/3.0/pl/deed.en. 